\title{
Applying Numerical Modelling to Pillar Design in South African Mines — An Initial Study
}

\author{
K. Naidoo University of Pretoria, South Africa \\ M.F. Handley University of Pretoria, South Africa
}

A.R. Leach Itasca Africa Pty Ltd, South Africa

\begin{abstract}
The use of bord and pillar mining methods is a favoured approach to mining in many shallow tabular mines, where the orebody dip is relatively flat. Although much work has been done on design methods for pillars under various rock mass conditions, there seems to be a lack of consensus in terms of a uniform methodology that should be used throughout the mining industry. Moreover, there is no synergy between the coal, hard rock gold and platinum mines and the iron ore and manganese mines that use this method of mining. The purpose of this paper is to present the results of a preliminary analysis that is being carried out to try and find the 'Holy Grail' in the form of a generalised pillar design criterion or formula that is applicable to all mining environments and all modes of failure. Numerical modelling has been performed to ascertain the mechanism of failure in a range of cases and the effect that changes in pillar dimension may have had on pillar stability. At this time only square pillars have been considered.
\end{abstract}

\section{Introduction}

Bord (or room) and pillar mining is a favoured approach in many shallow depth and near horizontal tabular mining operations in South Africa, including coal mines, plus hard rock gold, platinum, chrome and manganese. Where pillars are intended to be stable and remain intact, most pillar design involves the use of empirical formulae. However while much research work has been done on coal pillar formulae and, while there are many rules of thumb for applying formulae in various environments, there are noted gaps in the hard rock design methodology and designs often appear conservative. In part this is the result of a scarcity of underground data on comparable hard rock failed and intact pillar cases that would allow thorough calibration of empirical formulae in the same way as coal formulae have been calibrated.

As a result, and as an alternative means of testing pillar design in a harder, more brittle, rock mass environment, a programme of numerical modelling has been used to assist and determine a pillar strength assessment methodology. The key focus of this work will be to try and develop some guidelines to help in providing a generalised design methodology for room and pillar workings in all mining environments in South Africa. This paper will highlight some of the findings of what is still a work very much in progress, focussing on pillar strength assessment.

\section{Existing pillar design methods in South African mines}

Before considering numerical models a brief review of current design methods is useful. Most layout designs in South African mines makes use of empirical pillar strength formulae such as those of Salamon and Munro (1967) and Madden (1987) for coal, and Hedley and Grant (1972) in hard rock cases. In general these formulae derive strength for failure of the pillar itself, though whether by crushing of the centre of the pillar, or through damage to adjacent strata is unclear. Generally the empirical formulae focus only on the strength of the pillar and not the enclosing strata. All these formulae make use of some form of parameterised width to height ratio to describe the geometry of the pillar, multiplied by a 'unit rock mass strength term', often referred to as $\mathrm{K}$, thought of as representative of the strength of a cubic metre of the rock mass. There is no consistent methodology to determine K. Options range from specific values, e.g. a value of 7.2 MPa for coal pillars derived by Salamon and Munro (1967), or determining a rock mass strength from rock mass ratings such as the DRMS (Design Rock Mass Strength, Laubscher, 1990), or taking a value that is between one and 
two-thirds of the laboratory uniaxial compressive strength (UCS) (Jager and Ryder, 2003). Consequently the range in possible strengths that can be estimated for these pillars using an empirical method can be very broad. Furthermore these empirical formulae do not cope with situations where the rock mass consists of various units of different strength. One of the main objectives behind the work reported in this paper has been to attempt to derive a method where results are repeatable, predictable and less open to conjectural selection of formula parameters.

A further aspect to account for in designing any pillar is the possible mechanism by which the pillar fails. For example, a narrow pillar in a relatively homogeneous rock mass may fail through collapse (crushing of the pillar core). If the roof or floor strata are weak, however, the pillar may preferentially fail by punching. For wide pillars, whatever the nature of the rock mass, foundation failure may occur. In some situations it is required that a pillar crushes rather than is stable. Given these different modes of failure it is perhaps optimistic to expect to drive a single unifying formula for pillar strength, and the result (as shown later in this paper) may be a series of overlapping criteria to define pillar stability as a function of pillar size for different modes of failure, based on the local geology.

\section{Methodology}

It has been considered that a good starting point to reassess pillar size and strength relationships is to make use of numerical models to examine pillar load and failure mechanisms for a range in pillar sizes and stratigraphic conditions. Methods are reasonably well established and tested worldwide to derive input properties for numerical models based on rock mass ratings and laboratory strengths, which are generally readily available, or easily compiled, in any mining situation. It is thought that these characteristic properties can also be used to derive input parameters for any derived pillar strength formula. For the purpose of this paper, Fast Lagrangian Analysis of Continua in 3D (FLAC3D), developed by Itasca (2000) was used in the modelling process. FLAC3D is a finite difference code for analysis of geomechanical problems consisting of various analytical stages. The code can be used to simulate the behaviour of structures built of soil, rock or other materials, which may undergo inelastic deformation when their yield limit is reached. The rock mass is represented by rectangular and wedge shaped elements within a three dimensional grid, which is adjusted to fit the shape of the object modelled. Each element behaves according to a prescribed linear or non-linear stress/strain law in response to applied forces or boundary constraints (Itasca, 1997).

\subsection{Model objectives}

While a broad guide to best practices on pillar design in the mining industry can be gauged from current mining operations and a review of the literature, there are a number of gaps that are best investigated using numerical models. What is likely to be obtained from this study would be a combination of using numerical models and observations to develop a methodology for pillar design in hard rock mines in South Africa. These areas include:

- A quantification of the relative merits of varying pillar sizes under identical geotechnical conditions, where quantification is in terms of rock damage and deformation around the pillar.

- The effect of varying rock mass strength and geological stratigraphy on pillar behaviour.

- The effect of varying rock mass properties on damage patterns around pillar.

- The effect of varying dimensions for pillars at various depths.

- The effect of varying loading rates on the pillars.

In this paper the results of a series of models where one set of rock mass conditions has been used (and are uniform through the model) will be reported. Changes in rock mass conditions provide similar results, however, analyses with layered stratigraphy comprising units of varying strength remain to be completed.

\subsection{Description of the models}

Models have been run with width to height ratios of 0.6 to 10. An example of the typical pillar model geometry is shown in Figure 1. Quarter symmetry about the pillar centre was used to reduce model size. In 
all cases the orebody was assumed to be $1.5 \mathrm{~m}$ thick. Cubic finite difference zones of $0.25 \mathrm{~m}$ size were used in the pillar and for the first $2 \mathrm{~m}$ into the hangingwall and footwall. The orebody was assumed to be horizontal.

It was found necessary to initially apply a hydrostatic stress of $1 \mathrm{MPa}$ throughout the model, to generate a small confinement in the pillar hangingwall and footwall. Thereafter, loading on the pillar was progressively increased by applying a slow velocity to the top of the model, progressively compressing the pillar. It is then possible to track the changes in average pillar stress and pillar damage as a function of the number of timesteps that the model has been run, or as a function of the total compression that the velocity has applied to the model, allowing the compilation of a load versus deformation graph for each pillar model case.

\begin{tabular}{|c|c|c|c|}
\hline \multirow{2}{*}{\multicolumn{2}{|c|}{$\begin{array}{c}\text { FLAC } \boldsymbol{C B D} 3.10 \\
\text { @2006 Itasca Consulting Group, Inc. } \\
\text { Step } 40000 \text { Model Perspective } \\
\text { 10:11:37 Wed Apr } 022008\end{array}$}} & \multicolumn{2}{|c|}{ Job Title: Load applied to $7.5 \times 7.5 \mathrm{~m}$ pillar and $10 \mathrm{~m}$ rooms } \\
\hline & & \multirow{5}{*}{$\begin{array}{l}\text { Approx } \\
50 \mathrm{~m}\end{array}$} & \multirow{5}{*}{ I $1.5 \mathrm{~m}$} \\
\hline $\begin{array}{l}\text { Center: } \\
\text { X: }: .375 \mathrm{e}+000 \\
\text { Y: }-4.375 \mathrm{e}+000 \\
\mathrm{Z}: 0.000 \mathrm{e}+000 \\
\text { Dist: } 1.150 \mathrm{e}+002\end{array}$ & $\begin{array}{l}\text { Rotation: } \\
\text { X: } 360.000 \\
\text { Y: } 0.000 \\
\text { Z: } 60.000 \\
\text { Mag.: } \quad 1 \\
\text { Ang.: } 22.500\end{array}$ & & \\
\hline \multirow{2}{*}{\multicolumn{2}{|c|}{$\begin{array}{l}\text { Block Group } \\
\text { Live mech zones shown } \\
\begin{array}{l}\text { av_pillar_vol } \\
\text { fw } \\
\text { hw } \\
\text { ore } \\
\text { ore }\end{array}\end{array}$}} & & \\
\hline & & & \\
\hline \multicolumn{2}{|c|}{$\begin{array}{l}\text { Itasca Consulting Group, Inc. } \\
\text { Minneapolis, MN USA }\end{array}$} & & \\
\hline
\end{tabular}

Figure 1 Typical quarter symmetry model geometry used to simulate a pillar and roof and floor strata in FLAC3D

It should be noted that the choice of loading rate is critical to the assessment of pillar strengths. There is a model dependent critical loading rate below which the peak pillar strength tends to a constant value. Above this an increase in load rate results in a progressive increase in modelled peak strength and the model absorbs and sheds applied load and fails in an erratic manner. The results of a series of models run with different loading rates are shown in Figure 2, with rates ranging from 1.0 e-5 to 2.5 e- 7 m per model time-step. This test case was for a $3 \mathrm{~m}$ wide pillar in a $1.5 \mathrm{~m}$ thick seam, giving a width to height ratio of 2 .

It should be noted that for most constitutive material behaviours in FLAC3D the model time has no direct relationship to a real time scale. The time-step has a duration that is influenced by model damping (to obtain equilibrium) and is sufficiently small that velocities generated within the model produce deformations that remain small in relation to zone size and do not easily lead to numerical instability in the model. 
Effect of loading rate on modelled peak stress

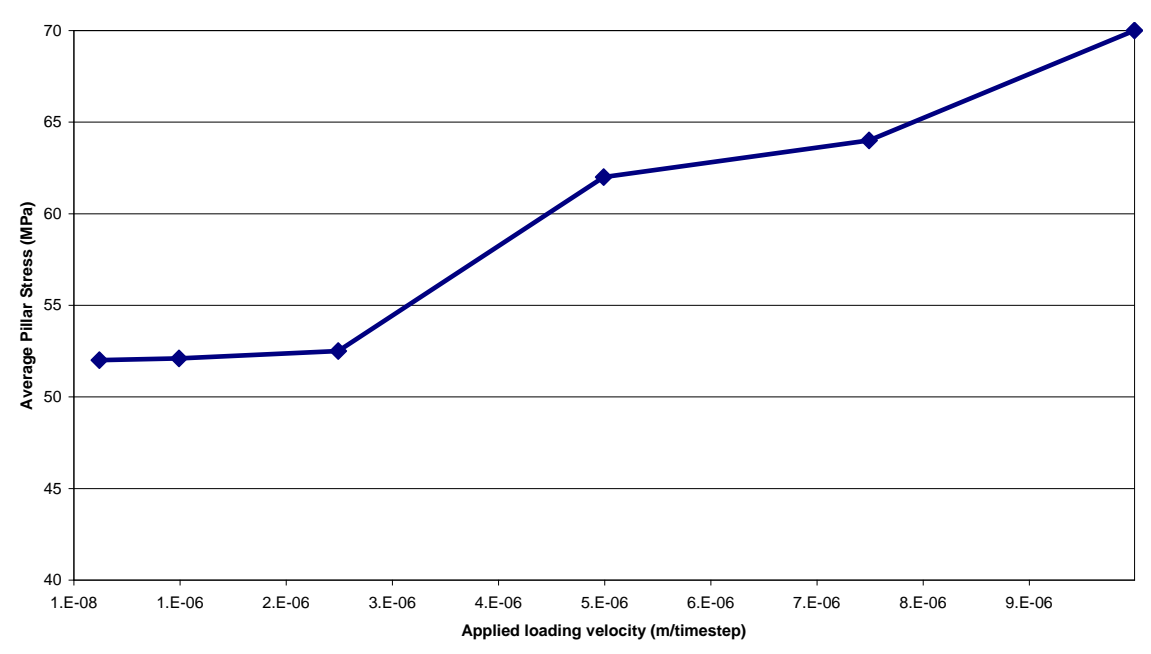

Figure 2 Effect of loading rate on modelled peak average pillar stress in a $\mathbf{3} \mathbf{m}$ wide pillar

\subsection{Rock mass properties}

For the purpose of numerical modelling using a continuum model, it was decided to adopt a Hoek-Brown criterion to predict rock mass failure. Rock failure in and around highly loaded pillars is extensile accompanied by shear failure on discontinuities. There is no adequate constitutive model to represent this type of failure. For this reason and for there to be a definitive method to choose rock properties that can be used in the models, the method proposed by Hoek in Roclab (2008) (Figure 3). This package is freely available from Rocscience. By using a specified UCS and GSI the Roclab program has been used to determine the necessary rock properties for use in the model.
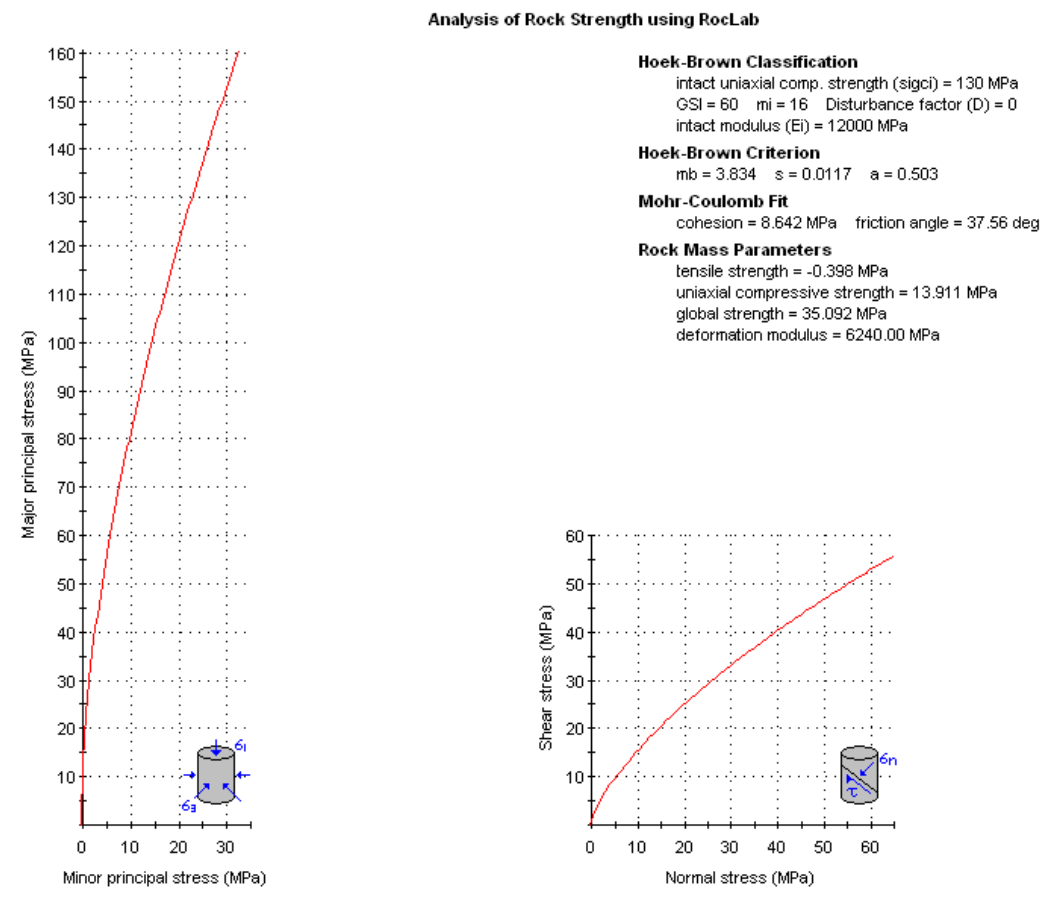

Figure 3 Roclab program used in the determination of rock properties (Roclab, 2008) 
Table 1 shows the estimates of the properties used in the models. The models described here all consider a rock mass comprising a single rock type and the properties listed are considered representative of general conditions in the igneous, largely pyroxenite and anorthosite, rock mass around the Merensky Reef in the Bushveld complex. The base properties were derived from the work done by Spencer (pers. comm., May 2008) and using the Roclab program. Note that both peak and residual strength properties are listed. It was found to be essential to include material softening behaviour to represent a pillar that has a peak strength then sheds load. Pillar behaviour can be influenced by the choice of parameters, plus the softening rate (where parameter values are reduced as a function of induced plastic strain) and the selection of residual parameters in particular is well recognised as an area with much uncertainty (Crowder et al., 2006). For these pillar models it was found that peak strengths remained similar provided that some form of moderate softening occurred and hence it was considered that a precise method for selection of residual parameters was not critical. For convenience it was decided to make use of the disturbance factor (D) in the Hoek/Roclab methodology where a value of $\mathrm{D}=0$ was used to estimate peak strengths and $\mathrm{D}=1$ in Roclab was used as an approximation to the loosening of the rock mass that occurs during failure. Technically this is a misuse of the D parameter, as D is intended as an indication of disturbance resulting from method of excavation. A Crowder, Coulson and Bawden reason that neither UCS, GSI, or D should be used to derive post-peak residual values of Hoek-Brown $\mathrm{m}$ and s parameters. This leaves no other method but back analysis to derive post peak values and hence it was decided to use $\mathrm{D}$ in the absence of other methods.

Using the parameters listed in Table 1, models were run first where only peak strength were used (nonsoftening material) and where strengths were allowed to soften from peak to residual values over a plastic strain of 0.01 (softening material).

\section{Table 1 Properties used in the models}

\begin{tabular}{lc}
\hline Properties & Pyroxenite \\
\hline UCS (MPa) & 130 \\
GSI /RMR 76 & 60 \\
$\mathrm{~m}_{\mathrm{i}}$ & 16 \\
$\mathrm{E}_{\mathrm{i}}(\mathrm{GPa})$ & 100 \\
$\mathrm{~V}$ & 0.25 \\
Rock mass strength $(\mathrm{MPa})$ & 35 \\
Em Young's modulus $(\mathrm{GPa})$ & 52 \\
Bulk modulus (GPa) & 35 \\
Shear modulus $(\mathrm{GPa})$ & 21 \\
D (peak) & 0 \\
mb (peak) & 3.834 \\
$\mathrm{~s}$ (peak) & 0.0117 \\
A & 0.503 \\
D (residual) & 1 \\
Mb (residual) & 0.919 \\
$\mathrm{~s}$ (residual) & 0.0013 \\
Critical strain $(\varepsilon)$ & 0.01 \\
\hline
\end{tabular}




\section{Model results}

In addition to merely considering the load-deformation and peak strength relationships of pillars of various size, the nature of failure within the models was also examined. It is well known that pillars can either fail through crushing of the core of the pillar, or through failure of the pillar hangingwall and footwall foundations. Consequently, in addition to running models where uniform failure criteria were applied throughout (and hence failure can occur anywhere), models were run to examine what happens if either the hangingwall-footwall units or the ore unit is made elastic, i.e. failure location is constrained. These cases are sketched in Figure 4.

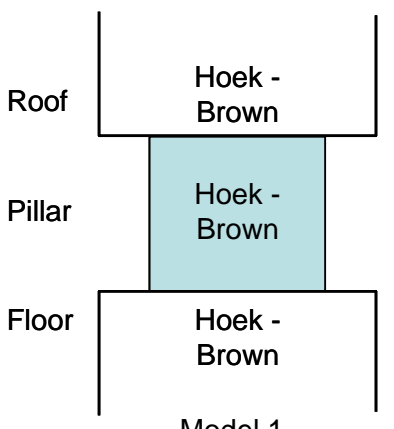

Model 1

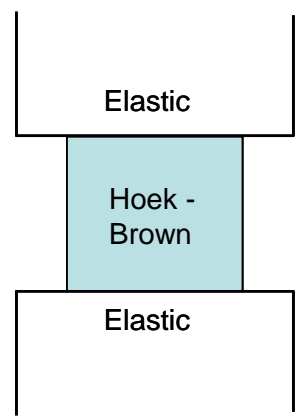

Model 2

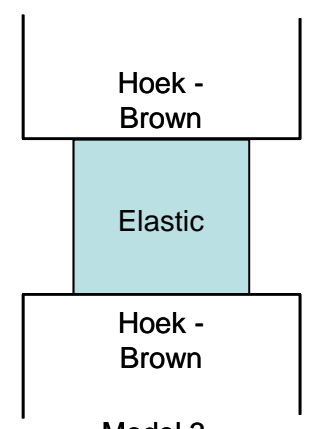

Model 3

Figure 4 The three conditions modelled using FLAC 3D

Figures 5 to 8 show graphs of applied pillar stress versus model timesteps (effectively total deformation applied to each model) for each of the model cases of various pillar sizes. Figures 10 and 11 make use of the peak stresses for each of these pillar cases extracted from the load-deformation curves and plotted against pillar width to height ratio. Briefly, some key effects can be observed.

In Figure 5, load-deformation curves for pillar models with a non-softening material strength relationship are shown (i.e. behaviour is elastic-perfectly plastic). The pillar graphs show there is no loss of strength after failure is initiated although strength settles at a constant value as further deformation occurs, and these final strengths are far higher than the peak strengths incurred in models where softening is permitted as shown in Figures 6, 7, and 8.

When a softening material is used, if failure is constrained within the orebody (hangingwall and footwall are elastic), there is a progressive increase in pillar strength as pillar width to height ratio is increased, eventually becoming exponential due to high confinement in the pillar core at very high widths.

If the orebody is made elastic and failure is only permitted in the hangingwall and footwall foundation units, resistance to failure is greatest at low pillar width to height ratios. As width increases the foundation strength tends towards a constant value, indicative of punching of the pillar into the strata. It would indicate a tendency towards a constant state of confinement that is independent of pillar width.

Where the entire model is allowed to fail, using a softening material behaviour it is clear that features of both models of failure either through crushing of the pillar core, or through punching of the foundation rocks may occur. In Figure 7, at width to height ratios up to approximately 4, the curve follows that for the model where failure is constrained to the orebody only. At greater width to height ratios some damage in the foundations is induced, causing a reduction in pillar strength and at width to height ratios above 6 pillar strength appears to level off at a constant value, due to foundation punching being the predominant mode. Note that this punching stress is however approximately one-third lower than that induced if the orebody is made elastic, indicating that crushing and deformation within the ore unit also influences the loads and failure mechanisms that occur in the foundations.

Figure 9 compares the distribution of damage that occurs within models of pillars with various width to height ratios, illustrating the change from pillar core crushing to foundation punching as width increases. 


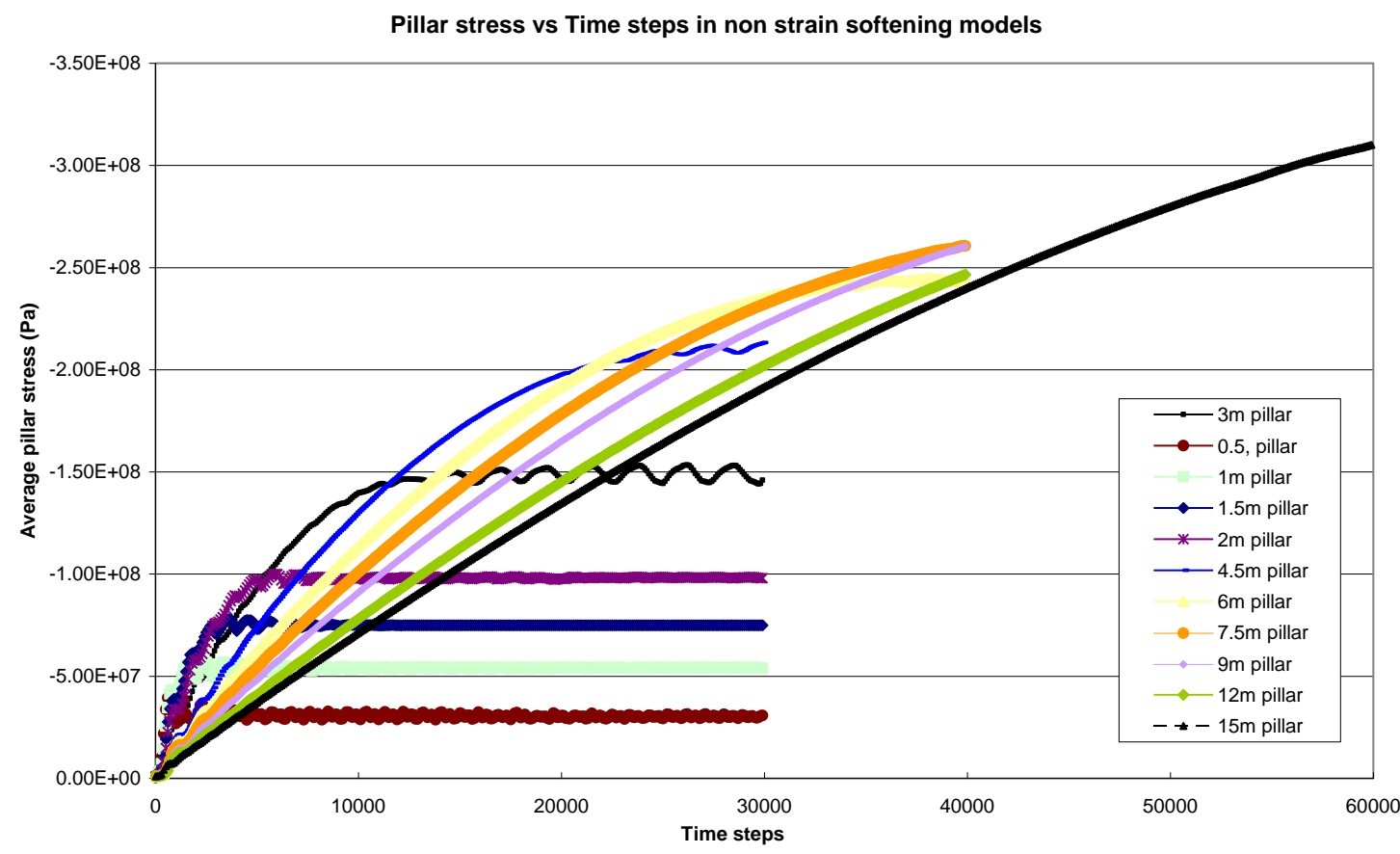

Figure 5 Average stresses induced in pillars as a result of compression-non strain softening (elasticperfectly plastic) model cases

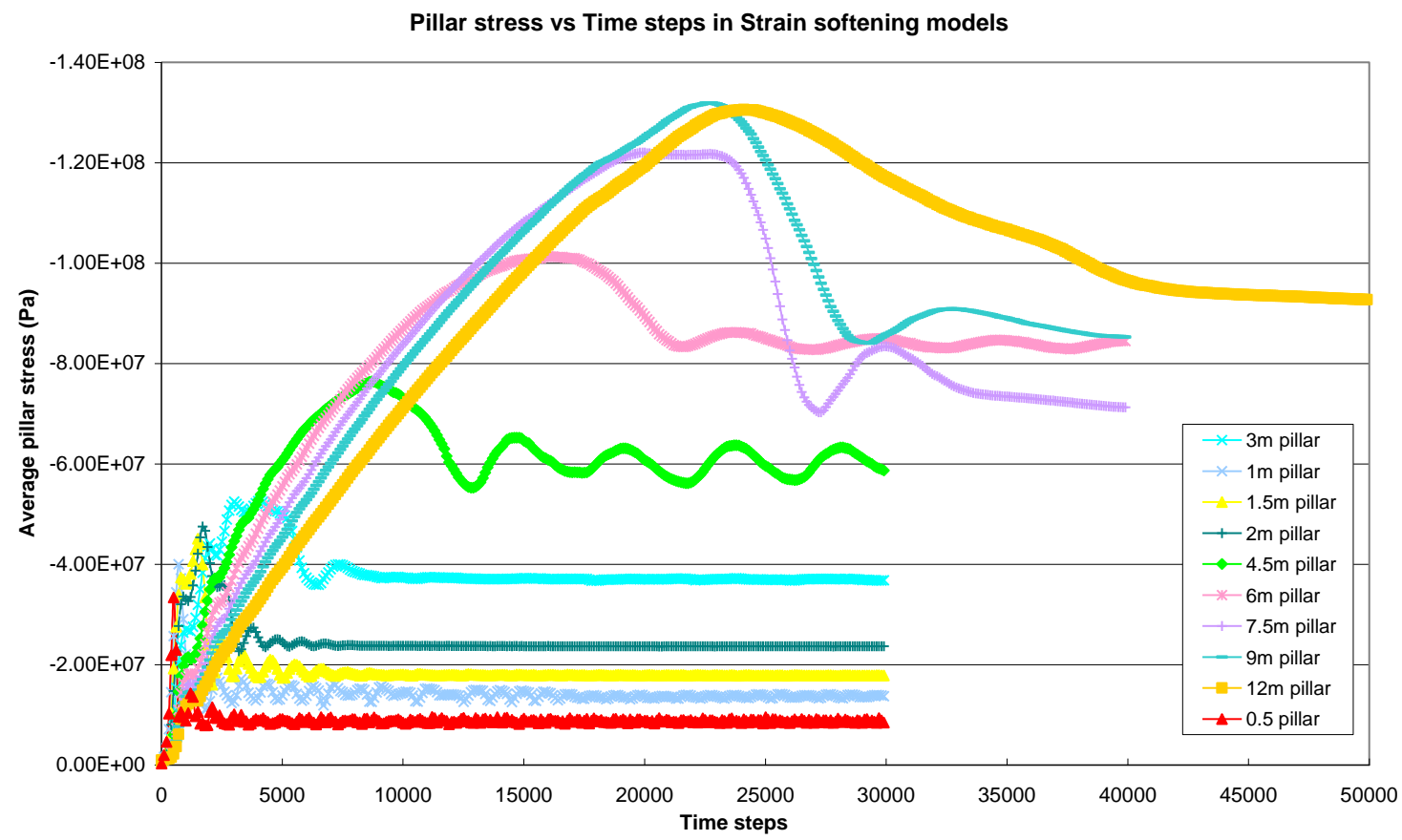

Figure 6 Average stresses induced in pillars as a result of compression-strain softening model cases 


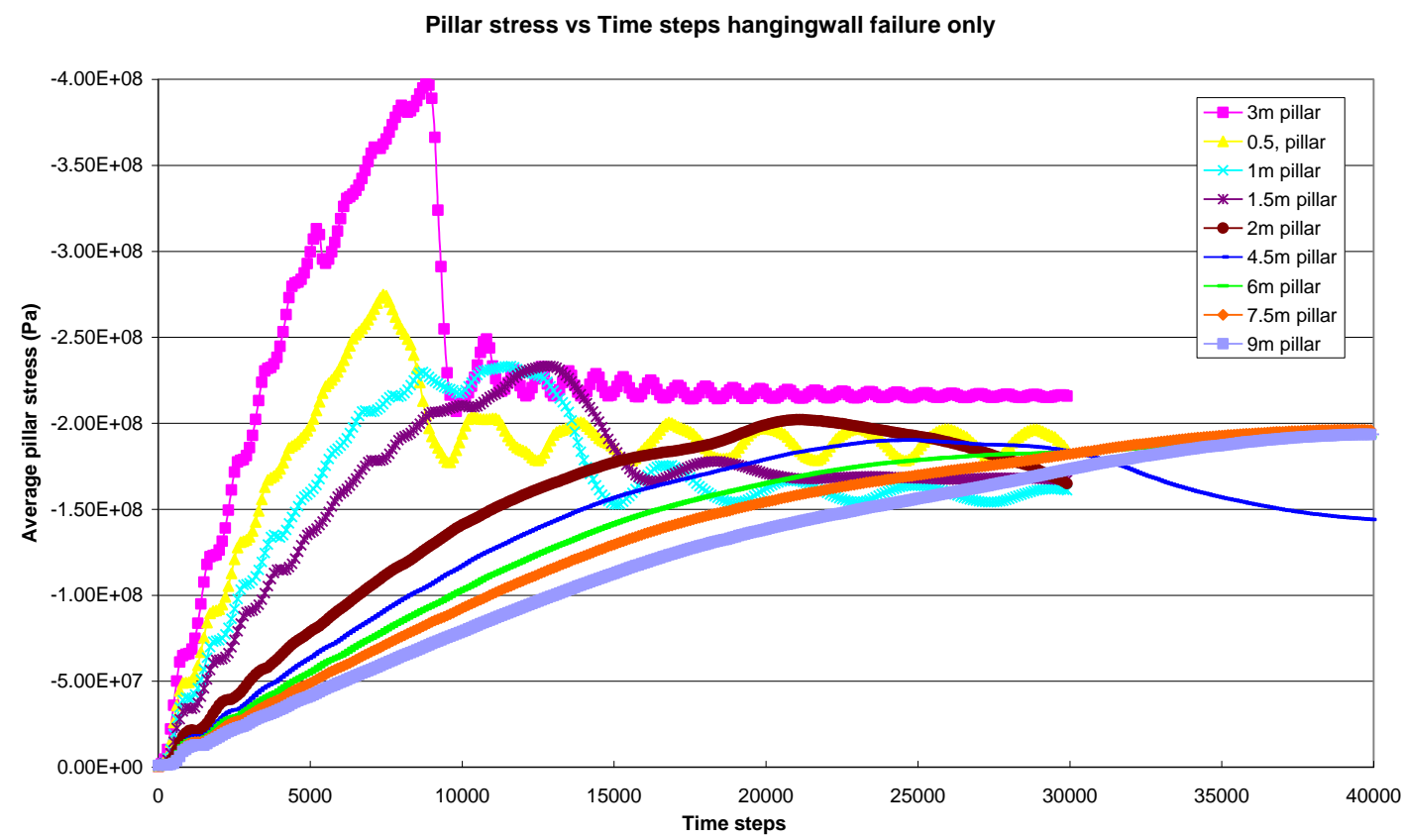

Figure 7 Average stresses induced in pillars as a result of compression-strain softening failure is permitted only in the hangingwall and footwall units, while the orebody is elastic and unable to yield

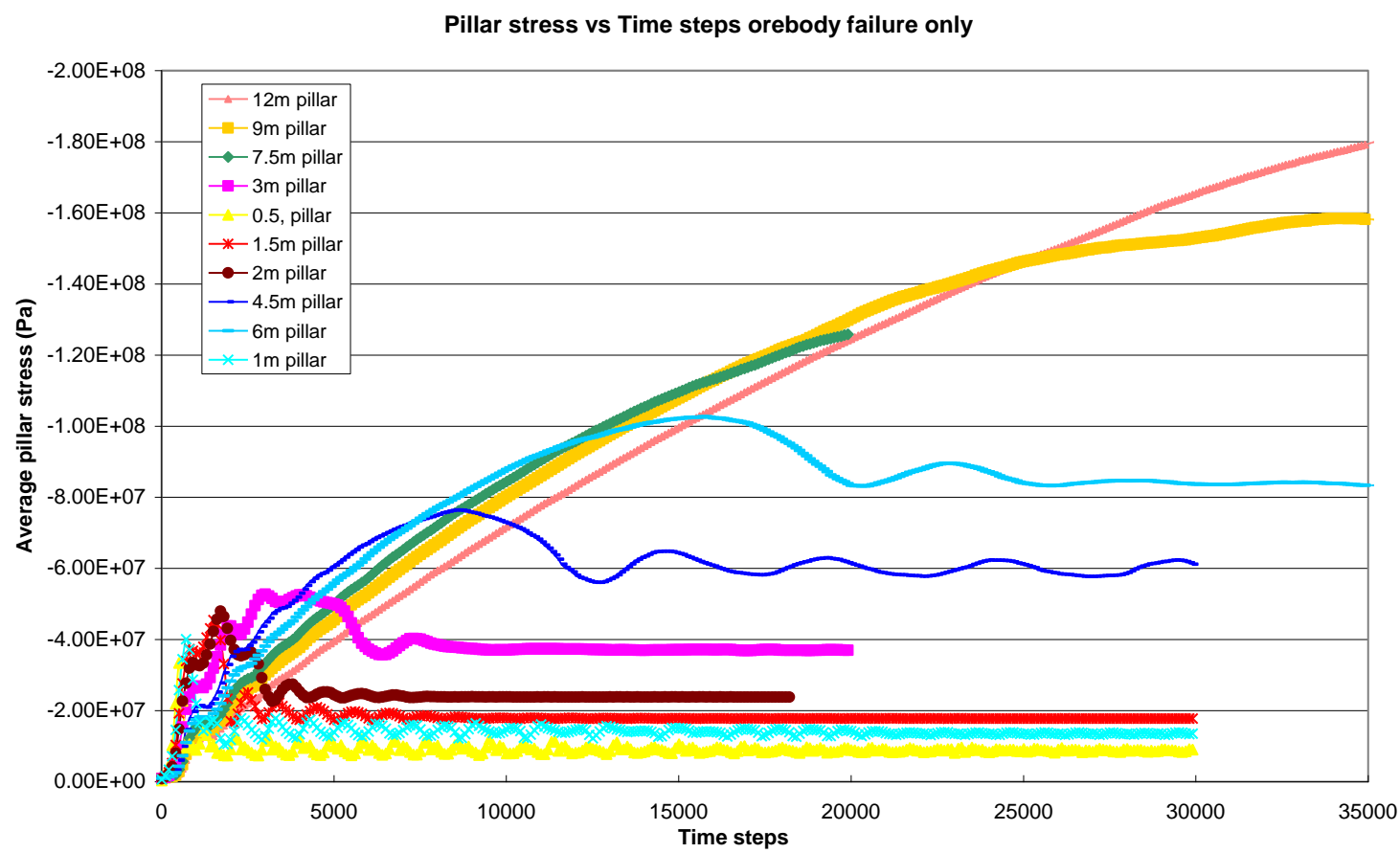

Figure 8 Average stresses induced in pillars as a result of compression-strain softening failure is only permiited in the orebody unit, while hangingwall and footwall units are elastic and cannot yield 


\section{Deformation}
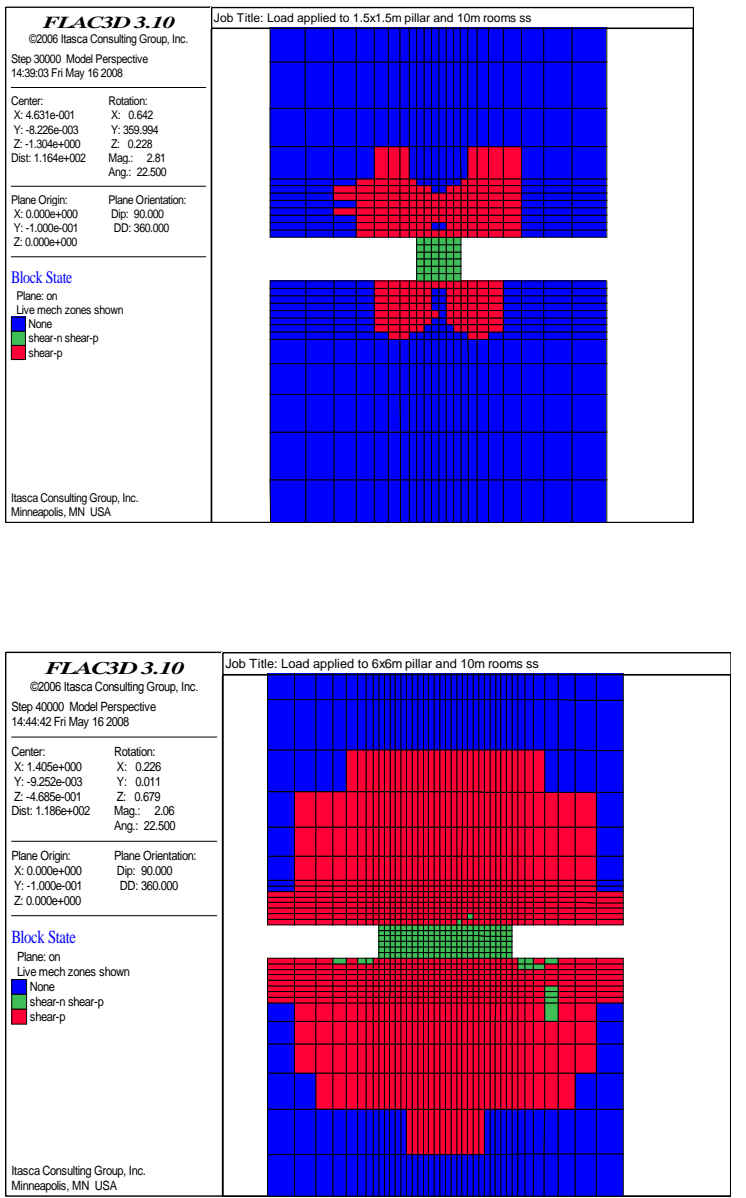

\section{Stress contours}

$1.5 \mathrm{~m}$ pillar

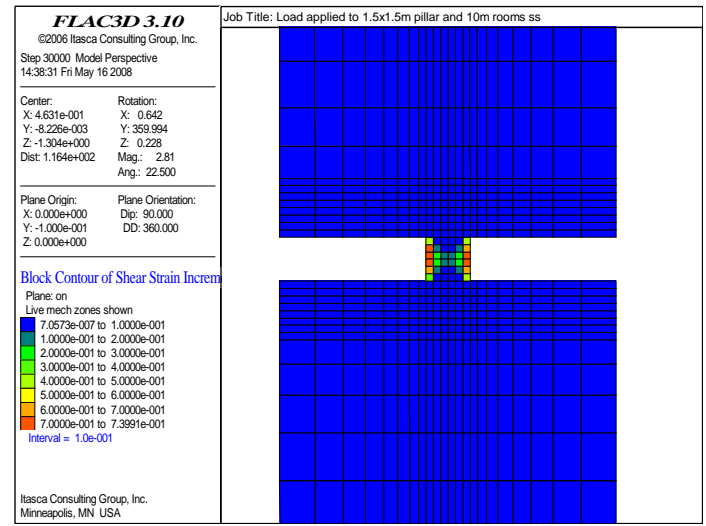

$6 \mathrm{~m}$ pillar

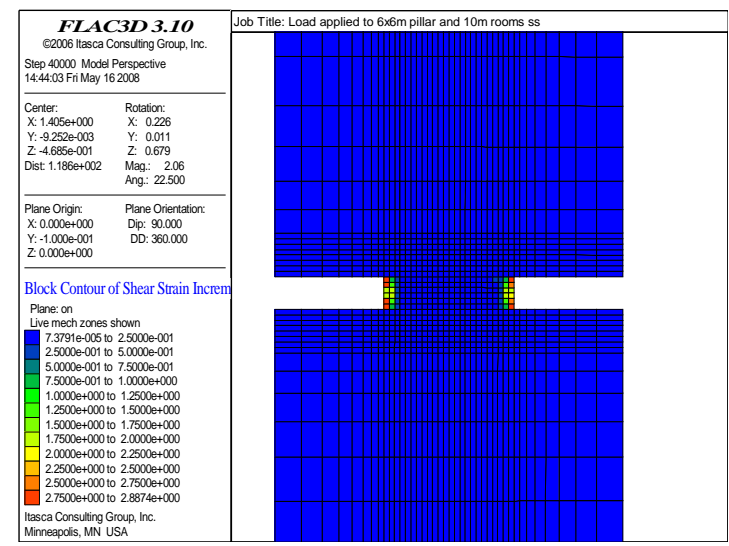

12 m pillar

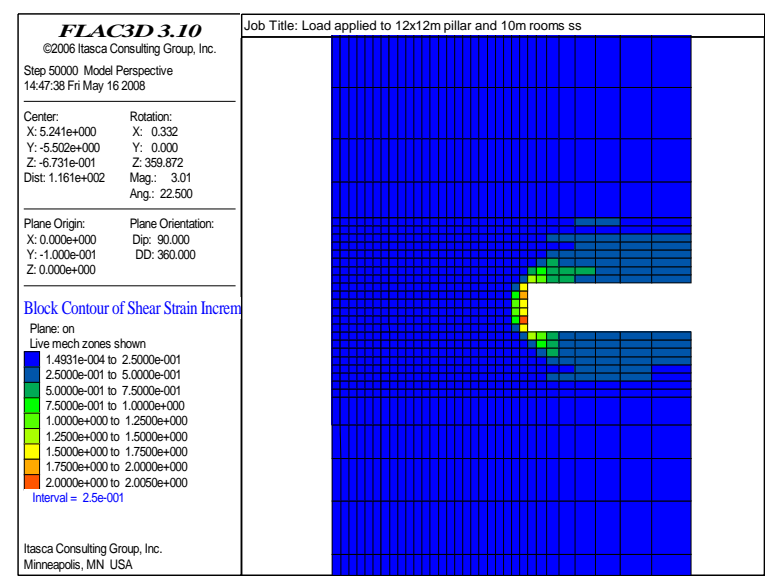

Minneapolis, MN USA

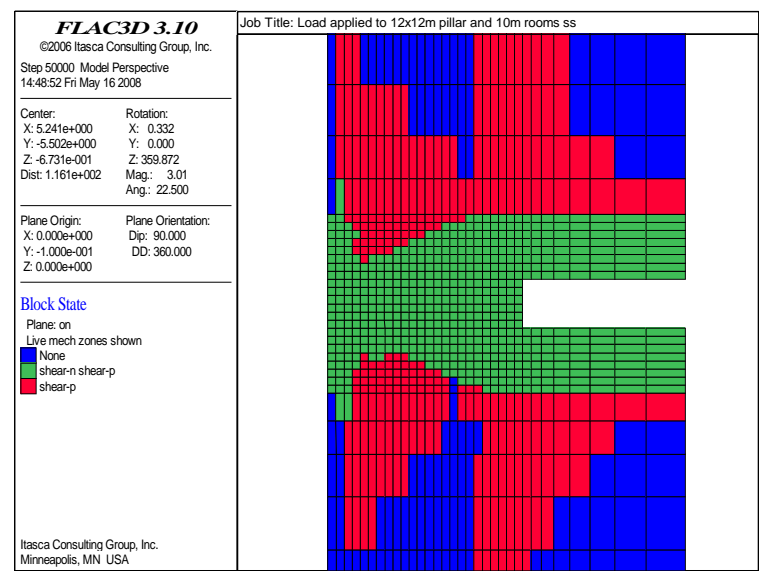

Figure 9 FLAC3D plots showing deformation and stress contours on various pillar sizes 


\section{Comparison of model results to empirical design criteria}

A review of the results indicated on the width to height ratio versus modelled pillar strength graph in Figures 10 and 11 suggests that it would be appropriate to test the model results against empirical strength formulae for narrow pillars, squat pillars, and for pillar punching.

For narrow pillars the most widely used formulae in hard rock operations is the formula of Hedley and Grant (1972):

$$
P_{\text {strength }}=K \frac{w_{\text {eff }}^{0.5}}{h^{0.75}}
$$

This formula is based on pillar width to height ratio (and is similar to Salamon and Munro's (1967) coal formula), multiplied by a unit rock mass strength, $\mathrm{K}$. There are various options for selecting $\mathrm{K}$, for example Laubscher's (1990) design rock mass strength (DRMS) is recommended by Stacey (2001). Another alternative is Hoek's rock mass strength calculated using Rocklab. Both this and the Lauscher method make use of both UCS and rock mass rating. The choice of this parameter obviously strongly influences derived strength. In South Africa's Bushveld mines a value of $1 / 3$ to $1 / 2$ the uniaxial compressive strength is frequently adopted as a universal value, however, this takes little account of the variability in rock mass conditions. For our adopted UCS for these models of $130 \mathrm{MPa}$ and GSI of 60, the following options for K are possible.

Table 2 Comparative estimates of rock mass unit strength for pillar formulae

\begin{tabular}{lll}
\hline Calculation Method & K Relation to UCS & Value of K \\
\hline Hoek & $0.26 \mathrm{UCS}$ & $35 \mathrm{MPa}$ \\
Mining industry & $0.33 \mathrm{UCS}$ & $43 \mathrm{MPa}$ \\
\hline
\end{tabular}

Using all both options for K, a Hedley-Grant strength curved is plotted against model results in Figure 10. It is generally clear in Figure 10 that for width to height ratios in excess of two, the correlation between model results and Hedley-Grant estimates start to deviate - the models indicate higher strengths. This formula tends to under-estimate the strength of wider pillars. Madden (1987) derived a squat pillar formula for coal pillars, which with the values of $\mathrm{K}$ listed above, can be applied to hard rock pillars also.

Madden's formula is as follows:

$$
P_{\text {strength }}=k \frac{R_{b}^{a}}{V^{a}}\left\{\frac{b}{\varepsilon}\left[\left(\frac{R}{R_{0}}\right)^{\varepsilon}-1\right]+1\right\}
$$

where:

$\mathrm{k}=$ unit strength of the rock mass in the pillar.

$\mathrm{R}_{0}=$ critical width: height ratio, defined as 5 .

$\varepsilon \quad=\quad$ rate of strength increase, here defined as 2.5 .

$\mathrm{a}=0.0667$.

$\mathrm{b}=0.5933$.

$\mathrm{R}=$ pillar width to height ratio.

$\mathrm{V}=$ volume of pillar.

This formula, shown in Figure 11, appears to give a reasonable match to model data over the range in width to height ratio from 2 to 5 , in the models considered. Note that in coal pillar design the squat pillar formula is assumed to apply to pillars where width to height ratio is larger than 5, so in hard rock pillars the effect appears to be seen with narrower pillars. Above a width to height ratio of 5, modelled behaviour appears controlled by pillar foundation punching failure, hence the continuous increase in 'pillar strength' is arrested. 
Empirical criteria for pillar punching into roof and floor strata are not well established. The Prandtl's wedge approach to footing bearing capacity design in civil engineering has been suggested for rib pillars, but is not well applied. In general, for wide, regional stability, pillars the hard rock South African mining industry tends to adopt a criterion where tolerable average pillar stress is 2 to 2.5 times UCS as a criterion for pillar foundation failure (Jager and Ryder, 2003). However, in this modelled instance where the original UCS is $130 \mathrm{MPa}$, a criterion much closer to 1 times the UCS appears more appropriate.

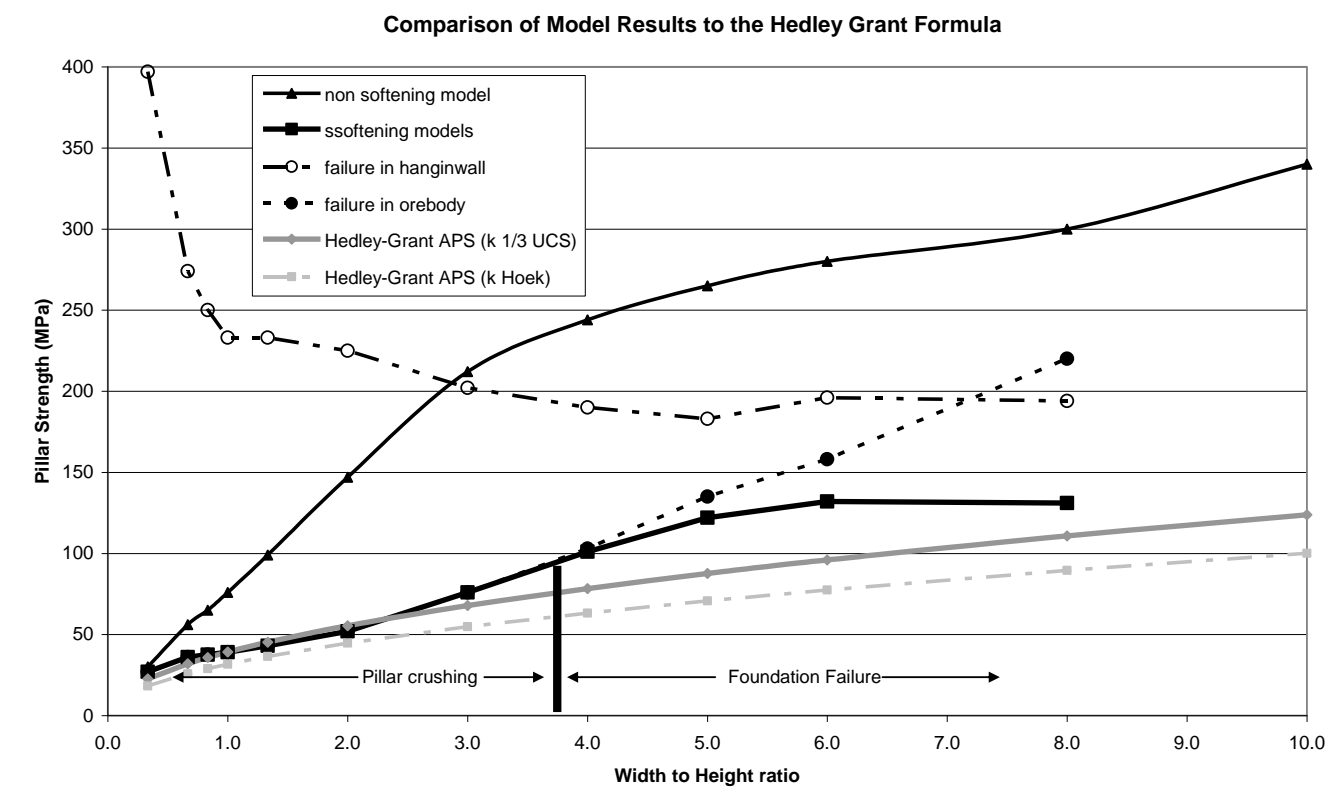

Figure 10 Comparison of Hedley and Grant formula and the model results

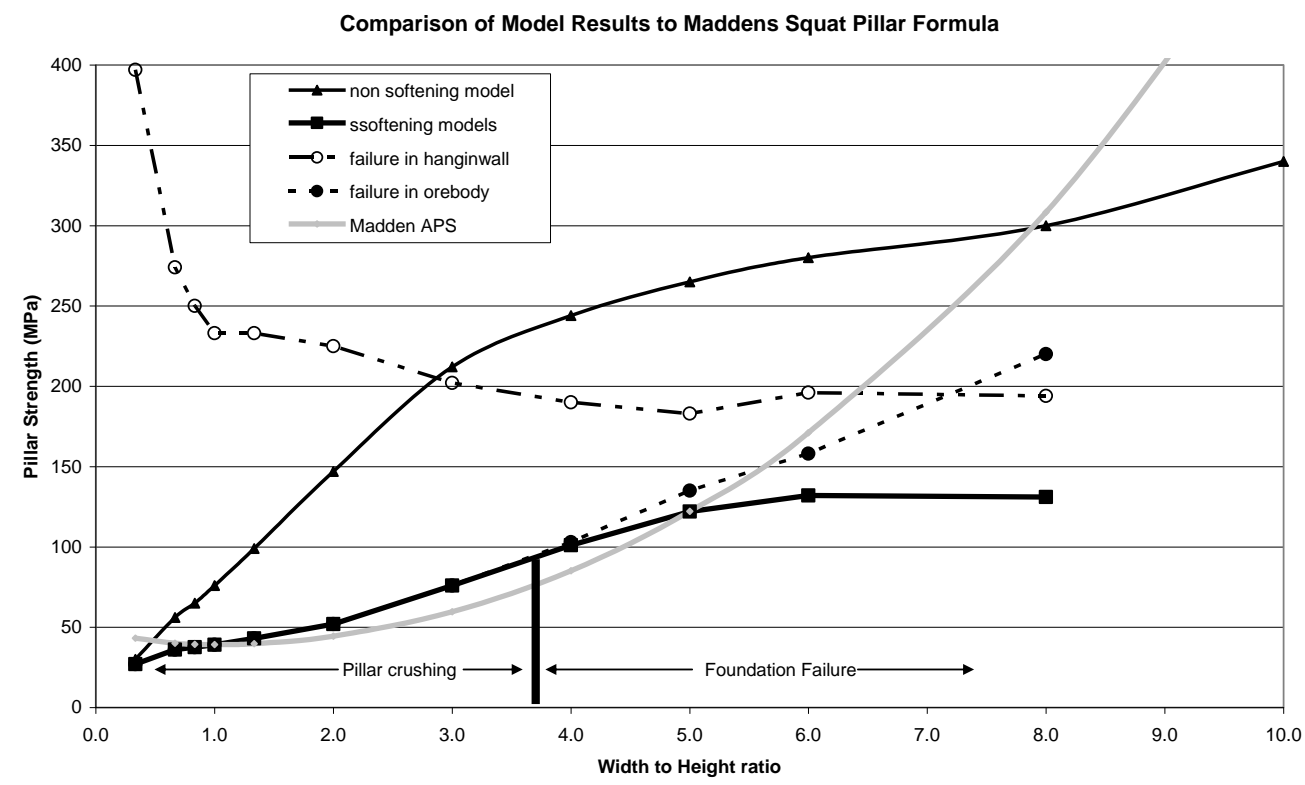

Figure 11 Comparison of Madden's squat pillar formula versus the model results 


\section{Conclusions}

As noted at the start of this paper, this assessment of pillar strength criteria is very much a work in progress and additional analysis is required to look at the effect of layered rock mass systems comprising units of varying strength, rock rating and stiffness, plus the effect of pillars that are rectangular or continuous and not just square. The results in the paper outline a comparison against models of a single rock type.

The main conclusions to be drawn are that:

Models indicate that pillar strength is strongly influenced by pillar width to height ratio which in turn strongly influences the pillar failure mechanism as a result of varying levels of confinement both in the pillar core and foundations.

Empirical formulae appear to give reasonable matches to pillar strengths over appropriate width to height ratio ranges. One of the limitations of empirical formulae however is the selection of an appropriate value for $\mathrm{K}$, the unit strength of the rock mass. Improved methods are required to link this to both rock mass classification and laboratory UCS values.

It is the intention of the authors to gather data relating to pillar damage, width to height ratio, and mining layout from a number of hard rock South African mines, which will enable an assessment of pillar loads versus damage and hence a calibration of numerical models. In particular this would assist in confirming methods for selecting rock material properties, and assist in identifying values for unit rock strength $\mathrm{K}$ in relation to UCS and GSI values. Further work is also required in the investigation of pillar loading systems.

\section{Acknowledgements}

Itasca Africa for their time and use of the FLAC3D code used in the numerical modelling process.

\section{References}

Crowder, J.J., Coulson, A.L. and Bawden, W.F. (2006) The Field-Scale Rock Mechanics Laboratory: Estimation of Post-Peak Parameters and Behaviour of Fractured Rock Masses. The 41st U.S. Symposium on Rock Mechanics (USRMS): 50 Years of Rock Mechanics - Landmarks and Future Challenges, held in Golden, Colorado, June 17-21, 2006.

Hedley, D.G.F. and Grant, F. (1972) Stope pillar design for the Elliot Lake uranium mines. Bulletin of the Canadian Institute of Mining and Metallurgy, Vol. 65, pp. 37-44.

ITASCA Consulting Group Inc. (2000) FLAC Fast Lagrangian Analysis of Continua. User's Guide. Second Edition, August.

ITASCA Consulting Group Inc. (1997) FLAC3D Fast Lagrangian Analysis of Continua in 3 Dimensions. User Manual.

Jager, A.J. and Ryder, J.A. (editors) (2003) A Handbook on Rock Engineering Practice for Tabular Hard Rock Mines. SIMRAC, Johannesburg, South Africa.

Laubscher, D.H. (1990) A geomechanics classification system for the rating of rock mass in mine design. Journal of the South African Institute of Mining and Metallurgy, Vol. 90, No. 10, pp. 257-273.

Madden, B.J. (1987) An introduction to the squat pillar design formula for collieries. Chamber of Mines Research Organisation Research Report No. 2/87. January.

Roclab program (2008) [online] Available from: www.roclab.com. [Accessed : 4/3/2008]

Salamon, M.D.G. and Munro, A.H. (1967) A method of designing bord and pillar workings. Journal of the South African Institute of Mining and Metallurgy, Vol. 67, pp. 68-78, September.

Stacey, T.R. (2001) Best practice rock engineering handbook for "other" mines. SIMRAC Project Number OTH602, Johannesburg, December. 